\title{
Mass eruption rates in pulsating eruptions estimated from video analysis of the gas thrust-buoyancy transition-a case study of the 2010 eruption of Eyjafjallajökull, Iceland
}

Tobias Dürig ${ }^{1,2^{*}}$, Magnús Tumi Gudmundsson', Sven Karmann², Bernd Zimanowski ${ }^{2}$ Pierfrancesco Dellino ${ }^{3}$, Martin Rietze ${ }^{4}$ and Ralf Büttner ${ }^{2}$

\begin{abstract}
The 2010 eruption of Eyjafjallajökull volcano was characterized by pulsating activity. Discrete ash bursts merged at higher altitude and formed a sustained quasi-continuous eruption column. High-resolution near-field videos were recorded on 8-10 May, during the second explosive phase of the eruption, and supplemented by contemporary aerial observations. In the observed period, pulses occurred at intervals of 0.8 to $23.4 \mathrm{~s}$ (average, $4.2 \mathrm{~s}$ ). On the basis of video analysis, the pulse volume and the velocity of the reversely buoyant jets that initiated each pulse were determined. The expansion history of jets was tracked until the pulses reached the height of transition from a negatively buoyant jet to a convective buoyant plume about $100 \mathrm{~m}$ above the vent. Based on the assumption that the density of the gas-solid mixture making up the pulse approximates that of the surrounding air at the level of transition from the jet to the plume, a mass flux ranging between 2.2 and $3.5 \cdot 10^{4} \mathrm{~kg} / \mathrm{s}$ was calculated. This mass eruption rate is in good agreement with results obtained with simple models relating plume height with mass discharge at the vent. Our findings indicate that near-field measurements of eruption source parameters in a pulsating eruption may prove to be an effective monitoring tool. A comparison of the observed pulses with those generated in calibrated large-scale experiments reveals very similar characteristics and suggests that the analysis of near-field sensors could in the future help to constrain the triggering mechanism of explosive eruptions.
\end{abstract}

Keywords: Explosive volcanism, Mass eruption rate, Near-field monitoring, Pulsating explosive eruptions, Eyjafjallajökull 2010

\section{Background}

The 2010 eruption of Eyjafjallajökull volcano demonstrated the need for a European response to the hazard of ash clouds from Icelandic volcanoes. The eruption was characterized by a several-kilometer-high volcanic plume that as a consequence of prevailing wind conditions resulted in the dispersal of ash reaching continental Europe (e.g., Arason et al. 2011; Langmann et al. 2011; Gudmundsson et al. 2012).

\footnotetext{
* Correspondence: tobi@hi.is

${ }^{1}$ Nordvulk, Institute of Earth Sciences, University of Iceland, Sturlugata 7, 107, Reykjavík, Iceland

${ }^{2}$ Physikalisch-Vulkanologisches Labor, Universität Würzburg, Pleicherwall 1, 97070 Würzburg, Germany

Full list of author information is available at the end of the article
}

Many ash plume models of long-lived eruptions assume a continuous steady emission of tephra at the volcanic vent (e.g., Sparks 1986; Woodhouse et al. 2013). However, the Eyjafjallajökull eruption was characterized by multiple closely timed explosions resulting in the release of discrete parcels of ash (Dellino et al. 2012) merging in a sustained eruption column at higher altitude. These bursts are here referred to as "ash pulses". The pulsating behavior was also detected in the velocity profile of the plume (Bjornsson et al. 2013) and in the infrasound signature of the eruption (Ripepe et al. 2013) and was quantified for 4 May in terms of number of pulses, pulse velocities, and pulse heights by using a thermal camera (Ripepe et al. 2013). 
It is plausible that pulsations, related to discrete magma fragmentation events in the volcanic conduit, can be a frequent phenomenon in explosive eruptions, but it is difficult to discern the pulses and study their initiation if the crater is not directly visible. Fortunately, the crater of Eyjafjallajökull was in clear view during the time period studied here, and the pulses were recorded at high definition by video cameras, allowing their nature and evolution to be studied. The results of our analysis are presented in this paper.

One of the most important parameters for the hazard assessment of explosive eruptions is the amount of volcanic material (i.e., tephra and gas) pushed into the atmosphere per unit time, i.e., the mass eruption rate (e.g., Sparks 1986; Sparks et al. 1997; Mastin et al. 2009; Kaminski et al. 2011). Real-time monitoring systems based on Doppler radar (e.g., Vöge and Hort 2009; Gerst et al. 2013), optical (e.g., Taddeucci et al. 2012; Valade et al. 2014), infrasound (see e.g., Johnson and Ripepe 2011; Ripepe et al. 2013), and electrical methods (Büttner et al. 2000) provide information that would allow near real-time estimates of the mass eruption rate. Existing methods, however, are affected by considerable uncertainties, with large variations between different estimates for the same eruption (for Eyjafjallajökull, see e.g., Woodhouse et al. 2013; Ripepe et al. 2013, Bursik et al. 2012; Gudmundsson et al. 2012). Since mass eruption rate is one of the key parameters of plume models, which in turn are used for initializing ash dispersal models (e.g., Bonadonna et al. 2012), there is a need for more reliable estimates of source conditions. Methods based on real-time observations, as the one we are proposing here, can therefore be valuable for monitoring eruption source parameters. The characterization of individual pulses and measurements of their duration, frequency, and size evolution with time and space are the aim of the present paper as they are of primary importance for defining the mass eruption rate and testing monitoring techniques.

The Eyjafjallajökull 2010 eruption can be subdivided into three main phases (Gudmundsson et al. 2012). The first explosive phase (14-18 April) was characterized by phreatomagmatic activity while the second explosive phase (5-17 May) was dry and fragmentation appears to have been purely magmatic (Dellino et al. 2012). A third phase, occurring in between the main ones, featured mixed mechanisms.

In this paper, we focus in particular on the period 8-10 May. We use photogrammetry for both analyzing frequencies ("Measurements of pulsation intervals" section) and expansion rates ("Measurements of pulse evolution" section) of pulses as they are released from the vent and also for deriving eruption source parameters of individual pulses ("Pulse volume at transitional level-methodology and results" and "Pulse velocity-derived model" sections). The characteristics of pulsation found for 8-10 May are compared with those reported before the onset of the second explosive stage ("Temporal changes in the pulsating behavior-comparison 4 May versus 8-10 May" section). In the next step ("Discussion of errors and approximation of results" section), we examine the link between the eruption source parameters of the discrete jets and the overall mass eruption rate derived by continuous ash plume models. Finally ("Link between pulses and magma fragmentation events in the conduit" section), the expansion dynamics of the Eyjafjallajökull jets are compared with pulses generated by large-scale experiments and inferences for real-time monitoring systems are briefly discussed.

\section{Methods}

\section{Measurements of pulsation intervals}

The video recordings used here were captured at $8-10$ May during a period of good visibility of the crater, allowing near-field analyses of the early expansion phase of the pulses. These high-resolution videos were taken at the summit caldera rim, $850 \mathrm{~m}$ to the north-west of the vent, near the nunatak Goðasteinn (Fig. 1). During this period, the vent geometry was characterized by a vent depth (i.e., the vertical distance from the active crater rim down to the level where the explosions originated) of $51 \pm 7 \mathrm{~m}$ and an inner vent diameter of 8-15 m (Dürig et al. 2015). The raw videos were recorded at HD quality $(1920 \times 1080$ pixels $)$ with a frame rate of $30 \mathrm{fps}$ and covered a total time interval of approximately $35 \mathrm{~min}$. Excerpts can be found in Rietze (2010) (see also Table 1).

A total of 502 pulses were visually detected during the $35 \mathrm{~min}$, with an average pulsation interval $t_{\text {pulse }}$ (i.e., the time interval from one ejection to the next) of $4.2 \mathrm{~s}$ (pulse frequency, $0.24 \mathrm{~Hz}$ ). The $t_{\text {pulse }}$ values were characterized by relatively large variations, ranging from a minimum of $0.8 \mathrm{~s}$ to a maximum of $23.4 \mathrm{~s}$ (see Fig. 2a). For the determination of the mass eruption rate (MER), it is crucial to check whether a correlation exists between the time interval between two pulses and the transported mass. Our video analysis for Eyjafjallajökull revealed that such a correlation exists: a significant difference was observed between the intervals of "strong" pulses-i.e., jets featuring "all-out" eruptive events in the videos-and those of "weaker" pulses, characterized by a jet diameter at the vent exit $d$ typically smaller than $50 \mathrm{~m}$. These two kinds of pulses (for the sake of simplicity here denoted as "type 1" and "type 2", see Figs. $2 b$ and 3 ) are easily distinguishable, as is also shown by the statistics of Table 2 . The average time $t_{\text {pulse }}$ between strong pulses (type 1 ) is approximately eight times longer than for jets of the smaller size category (type 2). 


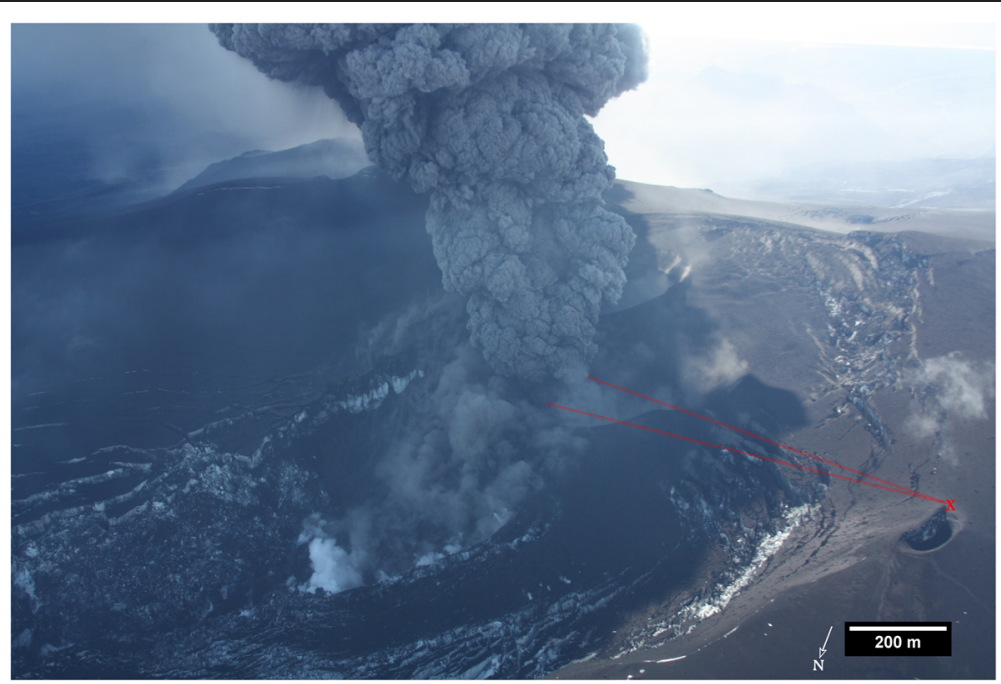

Fig. 1 Aerial photo from 08/05/10: The videos were recorded $850 \mathrm{~m}$ to the north-west of the vent (location X). The field of view is indicated by red lines. North is indicated by a white arrow. Photo: Thórdís Högnadóttir

\section{Measurements of pulse evolution}

Transitional level and pulse velocities

At a certain height, hereby denoted as "transitional level", a pulse leaves the region of gas thrust (negatively buoyant), crosses the level of neutral buoyancy, and enters a region in which buoyant convection takes over (see e.g., Sparks 1986). Buoyancy is reached because of the strong decrease of density of the hot gas-particle mixture, which is caused by the drastic decrease of particle volumetric concentration upon the combined effects of gas expansion by decompression and air entrainment. According to these considerations, the analysis of a pulse at the transitional level has the advantage of allowing the setting of two important parameters:

1. The pressure of the pulse $p_{\text {trans }}$ equals the ambient pressure $p_{0}$.

2. The density of the pulse $\rho_{\text {pulse }}$ can be approximated by the density of the ambient air $\rho_{0}$.

Table 1 Overview of the videos analyzed

\begin{tabular}{lllll}
\hline Video no. & Date & Time (UTC) & Duration (min) & No. of pulses \\
\hline 1 & 8.5 .2010 & $19: 35$ & $01: 56$ & 60 \\
2 & 8.5 .2010 & $21: 20$ & $03: 12$ & 58 \\
3 & 8.5 .2010 & $21: 39$ & $03: 27$ & 69 \\
4 & 8.5 .2010 & $21: 55$ & $01: 08$ & 7 \\
5 & 8.5 .2010 & $22: 00$ & $04: 53$ & 49 \\
6 & 9.5 .2010 & $20: 06$ & $00: 39$ & 4 \\
7 & 10.5 .2010 & $17: 28$ & $04: 14$ & 79 \\
8 & 10.5 .2010 & $18: 38$ & $06: 50$ & 97 \\
9 & 10.5 .2010 & $18: 49$ & $05: 36$ & 79 \\
\hline
\end{tabular}

Excerpts of these videos are found in Rietze (2010)
The two constraints form the basis of our estimate of the mass flux (see the "Pulse velocity derived model" section).

Figure 4b, c shows the continuation of the pulse evolution presented in Fig. 3e, $\mathrm{f}$ and illustrates the specific changes after entering the transitional level: The transition from the gas thrust stage to the convective buoyant regime is characterized by the distinct generation of vortices, considerable radial expansion, and the onset of typical convective motion patterns. Ring vortexes around momentum-driven jets can initially show very similar features (see e.g., Chojnicki et al. 2015) but are-in contrast to pulses entering the buoyant regime-characterized by a decoupling pulse tip, which pierces through the center of the mushroom cloud formed. In order to identify the moment of transition for an individual pulse, hereby denoted $t_{\mathrm{I}}$, it is therefore useful to study the dynamic behavior of the pulse front.

Vertical pulse velocity, and its evolution with time and height, is a relatively easy one-dimensional parameter to measure via video analysis. The maximum velocity of the pulse front is recorded as the pulse exits from the vent. The initial vertical velocities $v_{0}$ of the analyzed pulses ranged from 32 to $112 \mathrm{~m} / \mathrm{s}$, with an average value of $65 \mathrm{~m} / \mathrm{s}$ and a standard deviation of $19 \mathrm{~m} / \mathrm{s}$ (see Fig. 2c).

Figure $2 \mathrm{~d}$ presents vertical velocity curves of 16 representative pulses. The vertical velocity of a pulse front drops with height until it enters the transitional level. At this point, the velocity profile of a pulse front shows a significant change, often characterized by a distinct kink in the velocity curve, as it is also reported by Patrick et al. (2007) and Marchetti et al. (2009): the deceleration of the pulse front decreases significantly when reaching 

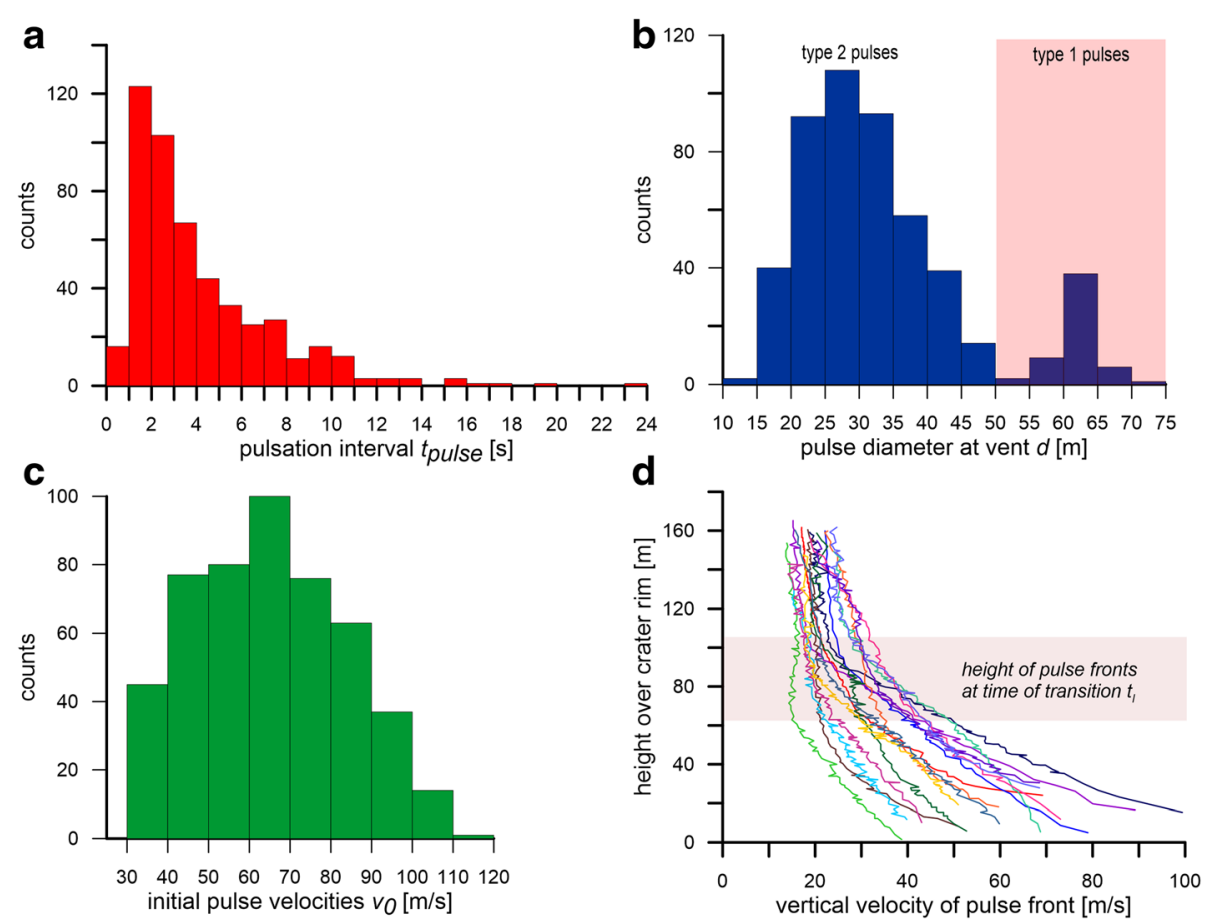

Fig. 2 Observation on Eyjafjallajökull ash pulses, 8-10 May 2010: a Histogram of pulsation intervals recorded: $t_{\text {pulse }}$ denotes the interval between two subsequent pulses. The values observed ranged between 0.8 and $23.4 \mathrm{~s}$. b Histogram showing the pulse diameters of 502 pulses measured at the vent. Two types of ash pulses can be discriminated by $d$ : "strong" pulses (type 1) and "weaker" pulses (type 2). c Initial pulse velocities $v_{0}$ of 502 pulses measured at vent exit. The average velocity recorded was $65 \mathrm{~m} / \mathrm{s}$. d Vertical velocities of 16 pulses. Many velocity curves show a clear change (marked by a "kink") when the pulse front left the momentum-driven stage and entered the level of transition. This is in agreement to the findings of earlier studies on ash pulses (see, e.g., Patrick et al. (2007), Marchetti et al. (2009)). The velocity changes are observed when the pulse fronts reached heights of approximately 60 to $105 \mathrm{~m}$ above the vent (zone highlighted in red)

the level of thermal buoyancy, eventually resulting in a (more or less) constant buoyant uplift velocity.

This characteristic change of pulse front dynamics marks the moment of transition $t_{\mathrm{I}}$, which can also be identified by a significant change in thermal radiation due to the increased entrainment of air (Marchetti et al. 2009) and-due to the prevailing wind conditions in the period analyzed-by the onset of enhanced lateral drifting of the now solely buoyancy-driven cloud (see Fig. 4c).

The measured heights of pulse fronts at the time of transition $t_{\mathrm{I}}$ ranged between approximately 60 and $105 \mathrm{~m}$ (see Fig. 2d). The location of the maximum horizontal width of a pulse at the moment of transition, denoted $d_{\text {trans }}\left(t_{\mathrm{I}}\right)$, is here defined to be the lower boundary of the transitional level (see Figs. 4 and 5). At this fixed (pulse-specific) height, the time-dependent pulse diameter $d_{\text {trans }}(t)$ increases, and it reaches a maximum at $t_{\mathrm{II}}$. The location of the pulse tip at that time can be defined as an upper boundary of the transitional level, meaning that above this height, convective buoyancy is the only significant uplift mechanism. According to these definitions, the transitional level of pulses recorded ranged approximately between 50 and $150 \mathrm{~m}$ above the vent exit.
The pulse velocity at the transitional level, $v_{\text {trans }}$ is defined by the vertical velocity of a pulse, measured in its center between $t_{\mathrm{I}}$ and $t_{\mathrm{II}}$, thus

$$
v_{\text {trans }}=\left(h\left(t_{I I}\right)-h\left(t_{I}\right)\right) /\left(t_{I I}-t_{I}\right)
$$

where $h(t)$ is the maximum height of the pulse at the time $t$.

While the visibility conditions at the vent exit permitted the determination of $v_{0}$ for all 502 pulses, measuring the pulse velocities at the transitional level $v_{\text {trans }}$ turned out to be more difficult in cases when a sequence of pulses merged at the transitional level. Therefore, a sample of 30 pulses was selected, which includes 5 "strong" type 1 pulses and 25 "moderate" type 2 pulses. By weighting the type-specific average values by the ratio $56: 446$ (see Table 2), the descriptive statistics of the total data set were calculated. The resulting weighted average of the convective uplift velocity at transitional level $v_{\text {trans }}$ is $22 \mathrm{~m} / \mathrm{s}$ with a weighted standard deviation of $10 \mathrm{~m} / \mathrm{s}$ (see Table 3 ).

\section{Projected area}

Although the pulse volume evolution does not necessarily correlate linearly with the expansion of the gas 

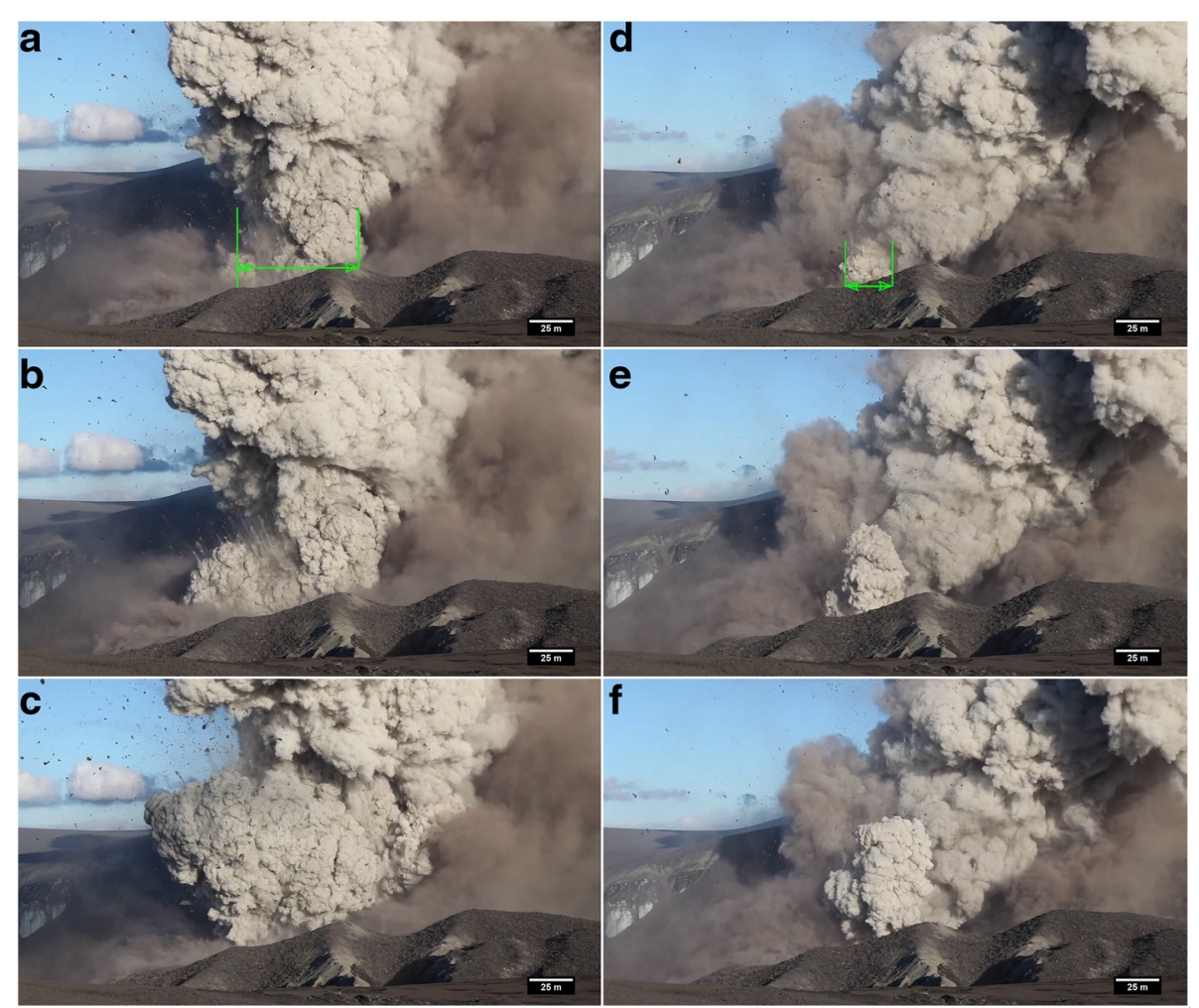

Fig. 3 Representative comparison between a "strong" type 1 pulse (a-c) and a "weaker" type 2 pulse (d-f). Green arrows mark the diameters of pulse fronts after the moment of discharge. A type 1 pulse features a column width at vent exit of more than $50 \mathrm{~m}$-in this example, $69 \mathrm{~m}$ (a), while type 2 pulses are characterized by a smaller diameter-here, $\sim 27 \mathrm{~m} \mathrm{(d)}$. a, $\mathbf{d}$ Pulses $0.2 \mathrm{~s}$ after their discharge. The contrast between both types becomes particularly evident for pulse interfaces during their gas thrust stage ((b) and (e), $0.7 \mathrm{~s}$ after discharge). After reaching the transition height ((f), $1.7 \mathrm{~s}$ after discharge), the evolution of pulses is determined by convective buoyancy ((c), $3.5 \mathrm{~s}$ after discharge). The evolution of the here presented type 2 pulse after entering the transitional level is shown in Fig. 4

volume, we hypothesized that the projected area $A$ in a vertical plane at right angles to the viewing angle of a three-dimensional expanding ash column can be used to follow the initial expansion dynamics of the pulse. This hypothesis is confirmed by the aircraft observation made on 8 May that indicates that the expanding ash cloud in the first couple of hundred meters above the vent had nearly a rotational symmetry, suggesting that $A$ is only weakly dependent on the viewing angle.

\section{Time of maximum expansion rates}

The instant of time $t_{\exp }$ when the expansion rate reaches its maximum is a useful parameter for quantifying the complex dynamics of a single eruptive pulse. Assuming

Table 2 Classification of pulses

\begin{tabular}{lllc}
\hline Pulse type & $d(\mathrm{~m})$ & No. of pulses & Average $t_{\text {pulse }}(\mathrm{s})$ \\
\hline Type 1 (strong) & $>50$ & 56 & 37.5 \\
Type 2 (,weaker") & $<50$ & 446 & 4.7 \\
\hline
\end{tabular}

Strong (type 1) eruptive pulses that feature ash columns with a large diameter at the vent exit $d$ are much less frequent than weaker (type 2) pulses that in the early stage of its evolution an ash plume is continuously expanding over height and time (and its volume is therefore enveloped by a convex hull), the instant of maximum volumetric expansion can be assumed as the maximum increase of $A$. Therefore, by using ImageJ (Schneider et al. 2012) as a photogrammetric tool, the projected area $A$ was quantified frame by frame by tracing the outlines of each plume. An example of this analysis is illustrated in Fig. 6 a.

In order to make pulses comparable, for each of them, the area measured at $t=0.8 \mathrm{~s}$ was considered: $A(0.8 \mathrm{~s})$. That time was chosen for two reasons: on one hand, according to the principles of error analysis, the uncertainties of $A$ are negatively correlated with their absolute values. This means that, as a standard, a value as large as possible has to be chosen.

On the other hand, the area to be measured needed to be unaffected by interference with a successive pulse. Therefore, the area value to be selected must correspond to a time still beyond $t_{\text {pulse }}$. By combining the two concepts, the best choice as a standardized area value for comparing pulses was $A(0.8 \mathrm{~s})$. 


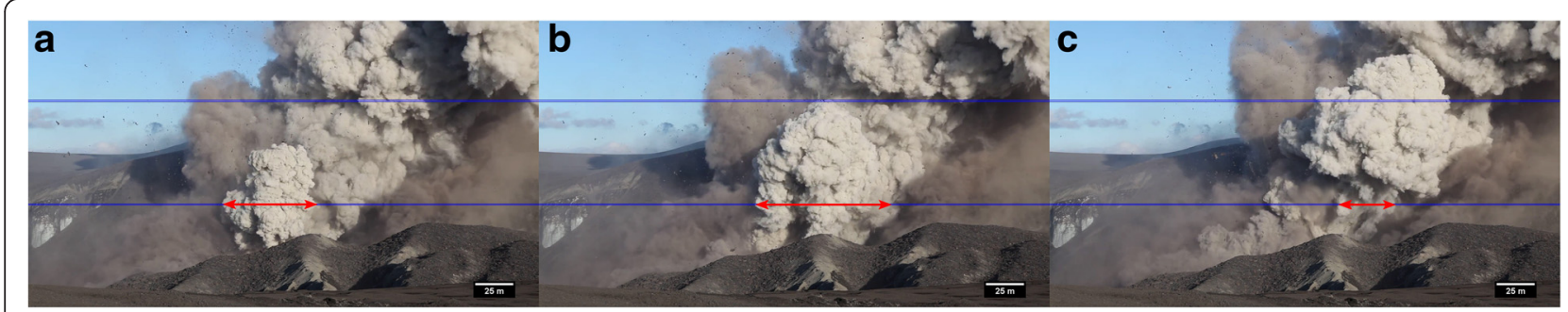

Fig. 4 Example for the transition of a pulse from gas thrust to convective buoyancy: a $1.7 \mathrm{~s}$ after occurrence, the pulse enters the transitional stage and subsequently starts to show clear signs of radial expansion. This moment coincides with a change in the vertical velocity of the pulse front (see Fig. 2d). In the case presented, the maximum pulse width $d_{\text {trans }}\left(t_{1}\right)$ (red arrow) is $60 \mathrm{~m}$. Its location determines the lower margin of the transitional level. Both boundaries of this region are indicated by blue lines. $\mathbf{b}$ The upper margin of the transitional zone is defined by the tip of the pulse when $d_{\text {trans }}(t)$ shows a maximum, here at $t_{\|}=3.9 \mathrm{~s}$. This particular pulse is characterized by a relatively low transitional uplift velocity $v_{\text {trans }}$ of $7.2 \mathrm{~m} / \mathrm{s}$. c At $t_{\| 1}=7.5 \mathrm{~s}, d_{\text {trans }}\left(t_{\text {III }}\right)$ has decreased to $d_{\text {trans }}\left(t_{1}\right) / e^{0.5}$, i.e., $36 \mathrm{~m}$. With a resulting $\tau$ of $5.8 \mathrm{~s}$, the resulting mass flux of solids ranged, according to Eqs. (13) and (14), between 0.9 and $1.5 \cdot 10^{4} \mathrm{~kg} / \mathrm{s}$, if a time base of $t_{\text {pulse }}=4.2 \mathrm{~s}$ is used. This number gives the mass eruption rate for the hypothetical case when all pulses during the eruption would have been identical with the presented one. The mass of tephra transported by this type 2 pulse ranged between 4.0 and $6.3 \cdot 10^{4} \mathrm{~kg}$
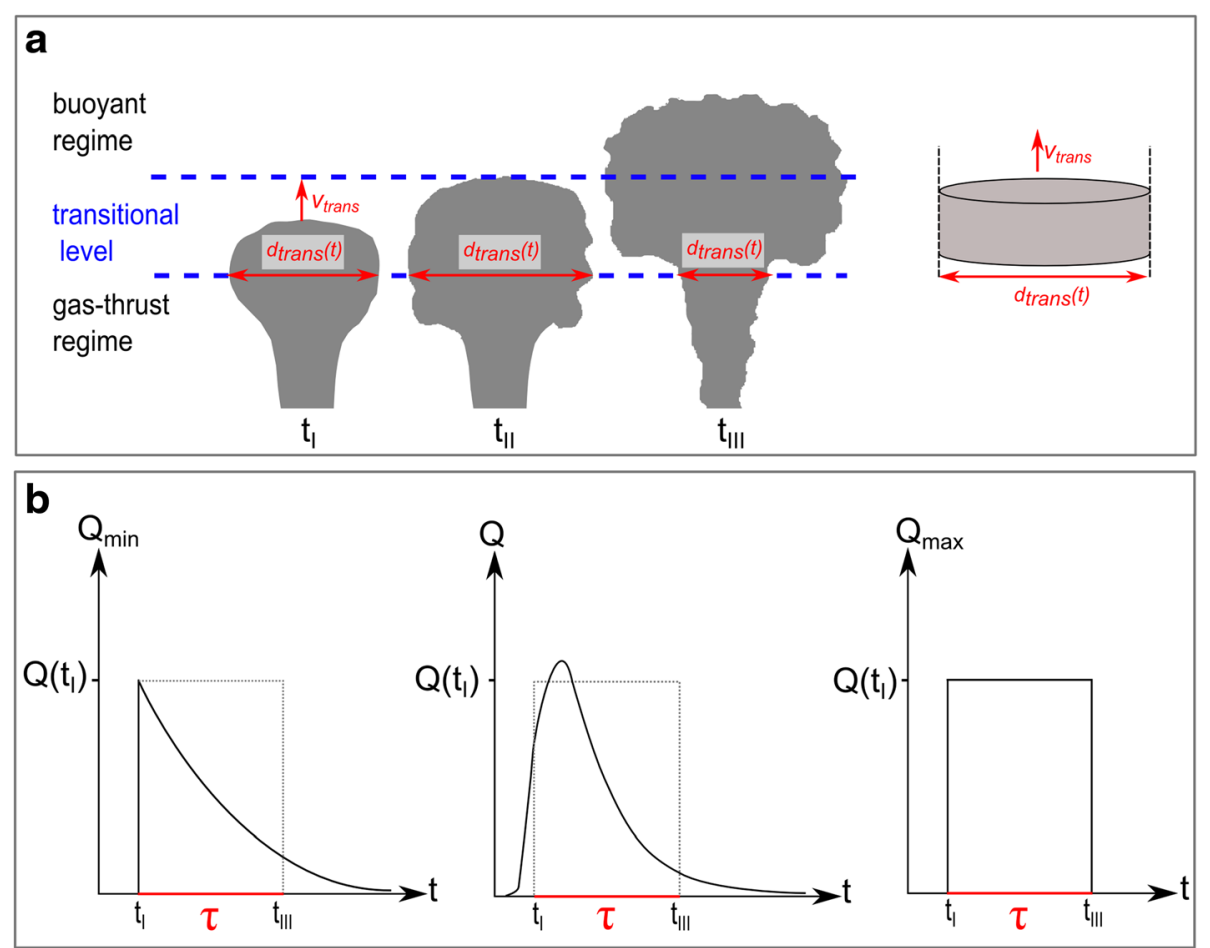

Fig. 5 Definition of the transitional level between gas thrust and buoyant regimes and pulse velocity derived model (PVDM) used to estimate the mass flux $Q$ of an individual pulse: a The onset of transition $t_{1}$ is marked by radial expansion, increased occurrence of vortices, and starting overturns of the pulse margins. The location of the maximum pulse width $d_{\text {trans }}\left(t_{i}\right)$ determines the lower boundary of the transitional level. The upper boundary is defined by the tip of a pulse at $t_{\| 1}$, when due to air entrainment, $d_{\text {trans }}\left(t_{\| 1}\right)$ is at maximum. The transitional uplift velocity $v_{\text {trans }}$ is measured between $t_{1}$ and $t_{\| 1}$. The PVDM approach approximates the volumetric flux as that of an "ash package" through a cylindrical cross section with $d_{\text {trans }}\left(t_{1}\right)$ being its diameter and $v_{\text {trans }}$ being its flow velocity, persisting for a duration $\tau$. This characteristic time parameter is determined by measuring the temporal distance between $t_{1}$ and $t_{I I I}$, i.e., the moment when the pulse diameter decreased to $d_{\text {trans }}\left(t_{1}\right) / e^{0.5}$. b By multiplying the volumetric flow rate with the density of the pulse (taken to be equal to that of the surrounding air at the transitional level), it is possible to calculate the peak mass flux $Q\left(t_{1}\right)$. Two cases are calculated, constraining the unknown flow rate evolution (center). While for a minimum estimate, an exponential temporal decrease of the flux is assumed (left), a maximum flow rate assumes a step function (right) which would correspond to a cylinder shaped ash package, as illustrated in a 
Table 3 Statistical results for PVDM applied to 30 pulses, assuming a pulse temperature of $480^{\circ} \mathrm{C}$

\begin{tabular}{|c|c|c|c|c|c|c|c|c|}
\hline & No. & & Average & St. dev. & Wt. average & Wt. st. dev. & SI units & Eq. \\
\hline \multirow[t]{2}{*}{$v_{\text {trans }}$} & 5 & Type 1 & 27.7 & 13.3 & 21.8 & 10.4 & $\mathrm{~m} / \mathrm{s}$ & (1) \\
\hline & 25 & Type 2 & 21.1 & 11.5 & & & & \\
\hline \multirow[t]{2}{*}{$\tau$} & 5 & Type 1 & 2.4 & 1.7 & 2.9 & 0.9 & s & (11) \\
\hline & 25 & Type 2 & 3.0 & 1.0 & & & & \\
\hline \multirow[t]{2}{*}{$d_{\text {trans }}\left(t_{1}\right)$} & 5 & Type 1 & 94.9 & 7.8 & 71.1 & 15.2 & $\mathrm{~m}$ & \\
\hline & 25 & Type 2 & 68.1 & 17.1 & & & & \\
\hline \multirow[t]{2}{*}{$Q\left(t_{1}\right)$} & 5 & Type 1 & $1.2 \cdot 10^{5}$ & $0.5 \cdot 10^{5}$ & $0.6 \cdot 10^{5}$ & $0.4 \cdot 10^{5}$ & $\mathrm{~kg} / \mathrm{s}$ & (8) \\
\hline & 25 & Type 2 & $0.5 \cdot 10^{5}$ & $0.4 \cdot 10^{5}$ & & & & \\
\hline \multirow[t]{2}{*}{$Q_{\text {tot_min }}$} & 5 & Type 1 & $0.5 \cdot 10^{4}$ & $0.1 \cdot 10^{4}$ & $2.2 \cdot 10^{4}$ & $0.7 \cdot 10^{4}$ & $\mathrm{~kg} / \mathrm{s}$ & (13) \\
\hline & 25 & Type 2 & $1.7 \cdot 10^{4}$ & $0.7 \cdot 10^{4}$ & & & & \\
\hline \multirow[t]{2}{*}{$Q_{\text {tot_max }}$} & 5 & Type 1 & $0.8 \cdot 10^{4}$ & $0.2 \cdot 10^{4}$ & $3.5 \cdot 10^{4}$ & $1.0 \cdot 10^{4}$ & $\mathrm{~kg} / \mathrm{s}$ & (14) \\
\hline & 25 & Type 2 & $2.7 \cdot 10^{4}$ & $1.2 \cdot 10^{4}$ & & & & \\
\hline \multirow[t]{2}{*}{$m_{t \_\max }$} & 5 & Type 1 & $2.9 \cdot 10^{5}$ & $0.6 \cdot 10^{5}$ & $1.5 \cdot 10^{5}$ & $0.7 \cdot 10^{5}$ & $\mathrm{~kg}$ & (18) \\
\hline & 25 & Type 2 & $1.3 \cdot 10^{5}$ & $0.8 \cdot 10^{5}$ & & & & \\
\hline \multirow[t]{2}{*}{$m_{g \_\max }$} & 5 & Type 1 & $1.7 \cdot 10^{5}$ & $0.4 \cdot 10^{5}$ & $0.9 \cdot 10^{5}$ & $0.4 \cdot 10^{5}$ & $\mathrm{~kg}$ & (20) \\
\hline & 25 & Type 2 & $0.8 \cdot 10^{5}$ & $0.5 \cdot 10^{5}$ & & & & \\
\hline
\end{tabular}

The convective uplift velocity at transitional level $v_{\text {trans, }}$ duration of ash transport at transitional level $\tau$, ash pulse diameter when entering the transitional level $d_{\text {trans }}\left(t_{1}\right)$, the peak mass flux $Q\left(t_{1}\right)$, the minimum and maximum of the total mass flux $Q_{\text {tot_min }}$ and $Q_{\text {tot_max }}$ and the maximum mass of gas ( $\left.m_{g_{-} \text {max }}\right)$ and tephra $\left(m_{t \_ \text {max }}\right)$ contained within a pulse are listed. Additionally, a reference to the respective equation of determination is given

The results of seven representative pulses are displayed in Fig. 7. Geometrically, all pulses expanded in a very similar way. Only the starting area value showed a significant variability. This is probably a consequence of both, the variable exit velocity and the comparatively large measurement uncertainties during the early stage of an ash pulse: erratic effects and deviations from rotational symmetry have the largest impact at the smallest areas. Moreover, it is to note that the "time gap" between two frames constrains the setting of the initial conditions. In the later stage of expansion, the normalized area values become more and more similar.

As an indicator of the volumetric expansion rate, the difference quotient $f\left(t_{2}\right)$ of the normalized areas between the times $t_{2}$ and $t_{1}$ was calculated, here defined as

$$
f\left(t_{2}\right)=\frac{A\left(t_{2}\right) / A(0.8 s)-A\left(t_{1}\right) / A(0.8 s)}{t_{2}-t_{1}}
$$

A typical result for $f(t)$ is shown in Fig. 8. According to the considerations above, the time of maximum expansion $t_{\exp }$ can be easily identified by the peak in the diagram. In the example of Fig. 8, the peak is at $0.40 \mathrm{~s}$. The mean of $t_{\exp }$ was $0.42 \mathrm{~s}$ with a standard deviation of $0.08 \mathrm{~s}$.

\section{Pulse volume at transitional level-methodology and results}

The pulse volume at transitional level $V_{\text {trans }}$ can be approximated by assuming it to be composed of the visible top volume $V_{\text {vis }}$ and the (hidden) volume within the conduit $V_{\text {con }}$ (see also Fig. 9):

$$
V_{\text {trans }}=V_{\text {con }}+V_{\text {vis }}
$$

Assuming a cylinder of length $z$ and radius $d / 2$ - where $z$ is the depth of the vent and $d$ is the diameter of the pulse at the vent exit-the in-conduit volume of a pulse can be approximated by

$$
V_{\text {con }}=\pi / 4 \cdot d^{2} \cdot z
$$

By analyzing the trajectories of high-speed ejecta using the same video data, it was possible to reconstruct their point of origin within the conduit, which gave a result of $51 \pm 7 \mathrm{~m}$ (Dürig et al. 2015).

The volume of the visible part of the ash pulse was calculated by means of ImageJ by determining the projected area $A$ and the horizontal distance $w$ between the center of mass $C$ and the vertical axis of symmetry (see Fig. 9). Assuming rotational symmetry, $V_{\text {vis }}$ is calculated by

$$
V_{\mathrm{vis}}=\pi \cdot A \cdot w
$$

By applying these relations, the pulse volumes $V_{\text {tran- }}$ ${ }_{s}\left(t_{I I}\right)$ of 16 cases, which covered the observed range of intensity of pulses, was calculated. For the 16 cases analyzed, type 1 pulses were overrepresented by a ratio of $5: 11$ with respect to the actual ratio of the raw data set (56:446, see Table 2); thus, the averages and standard deviations had to be re-weighted by the actual ratio. The results for $V_{\text {trans }}\left(t_{I I}\right)$ ranged between $0.2 \cdot 10^{5}$ and 10.5 . 

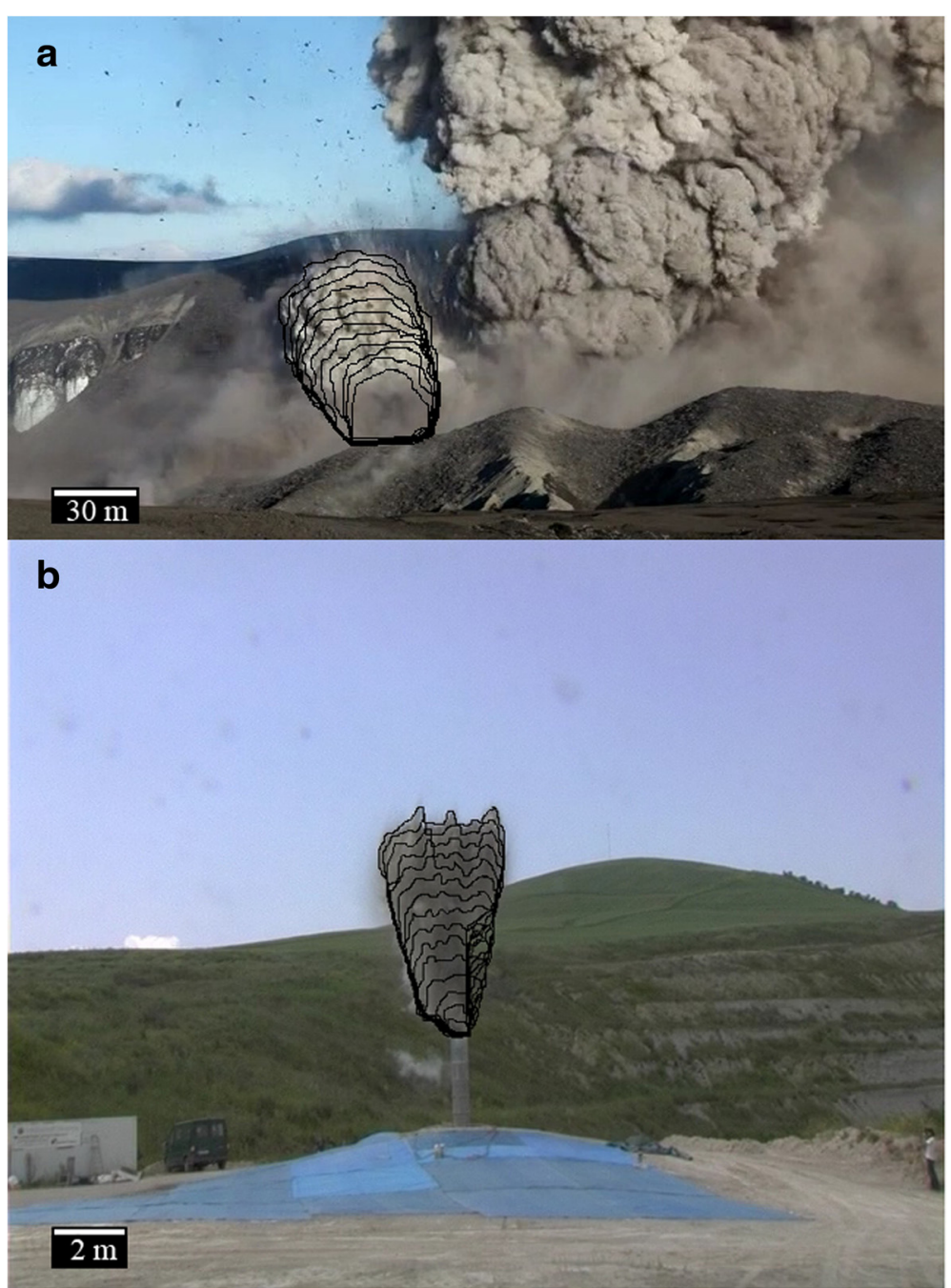

Fig. 6 a Example of an evolving ash pulse in the 2010 Eyjafjallajökull eruption, at 10 May, 18:39 (UTC). Its outlines were traced frame-by-frame, in order to obtain the expansion rates of the enclosed areas. Based on this parameter, it is possible to evaluate the dynamic development of the pulse. $\mathbf{b}$ Example of an experimentally generated ash pulse in the 2009 Spinazzola large-scale ash plume generation experiments (Dellino et al. 2010). Its dynamics have shown significant similarities to those of natural magmatic eruptions

$10^{5} \mathrm{~m}^{3}$, with a weighted average value of $2.0 \cdot 10^{5} \mathrm{~m}^{3}$ and a standard deviation of $1.5 \cdot 10^{5} \mathrm{~m}^{3}$ (see Table 4).

\section{Pulse velocity-derived model}

\section{Mass eruption rate at transitional level}

The pulse velocity-derived model (PVDM) relies on the fact that when entering the transitional level, the bulk density $\rho_{\text {pulse }}$ of a pulse, here assumed as a homogeneous mixture, can be approximated by the density of the ambient air $\left(1.05 \mathrm{~kg} / \mathrm{m}^{3}\right.$ at $1550 \mathrm{~m}$ a.s.l.; Ripepe et al. 2013). Furthermore, it can be assumed that at that stage, the pulse pressure is equal to the atmospheric value. The volume fraction $\phi$ of solids within a pulse made of a mixture of gas (density $\rho_{g}$ ) and tephra (density $\rho_{t}$ ) is given by

$$
\phi=\frac{\rho_{\text {pulse }}-\rho_{g}}{\rho_{t}-\rho_{g}}
$$

For the stage of Eyjafjallajökull eruption studied here, a DRE of $2200 \mathrm{~kg} / \mathrm{m}^{3}$ (Dellino et al. 2012) is used for $\rho_{t}$. In the cases considered in this article, with an average transitional level of $50-150 \mathrm{~m}$ over the vent, it is assumed that at this height, the mass loss due to decoupled ejecta is still small enough to be considered as a minor source of uncertainty. Forward looking infrared (FLIR) images taken on 8 May suggest that at the studied altitude, the ash pulses featured a temperature of $\sim 480{ }^{\circ} \mathrm{C}$ (see Fig. 10). In the absence of more precise thermal data, this temperature value is used as approximation for the bulk temperature of pulses. This temperature value is subject to considerable uncertainty, but as shown 


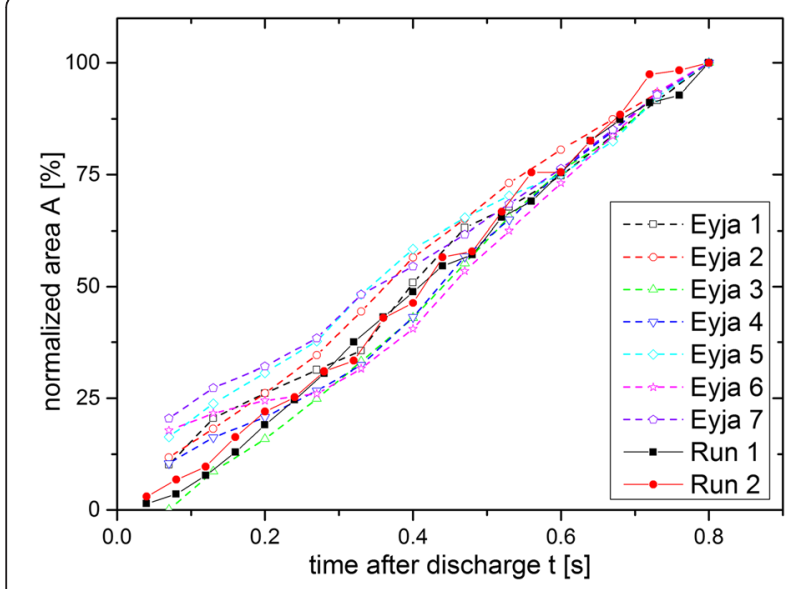

Fig. 7 Representative results for normalized areas: The labels denote the image sequence that was the source of the respective data set. During the 2010 Eyjafjallajökull eruption, Eyja 1 was recorded at 8 May, 21:35 (UTC), Eyja 2 to Eyja 5 at 10 May, 17:28-17:30, and Eyja 6 to Eyja 7 at 18:38-18:39. Additionally, the area development of two representative large-scale ash pulse generation runs performed in May 2009, described in Dellino et al. (2010) are depicted (unbroken lines). Run 1 was a collapse experiment on 18 May (see also Fig. 6b), Run 2 was a plume experiment using ash heated up to 543 K on 20 May

in the "Discussion of errors and approximation of results" section, the error arising from this uncertainty is not large.

The fact that during 8-10 May the eruption was in a dry magmatic phase (Dellino et al. 2012) leads us to the assumption that external water did not play a major role for the generation of the ash pulses. A temperature drop of the plume from $1000-1170{ }^{\circ} \mathrm{C}$ at the source (Keiding and Sigmarsson 2012) to $480{ }^{\circ} \mathrm{C}$ at the transitional level

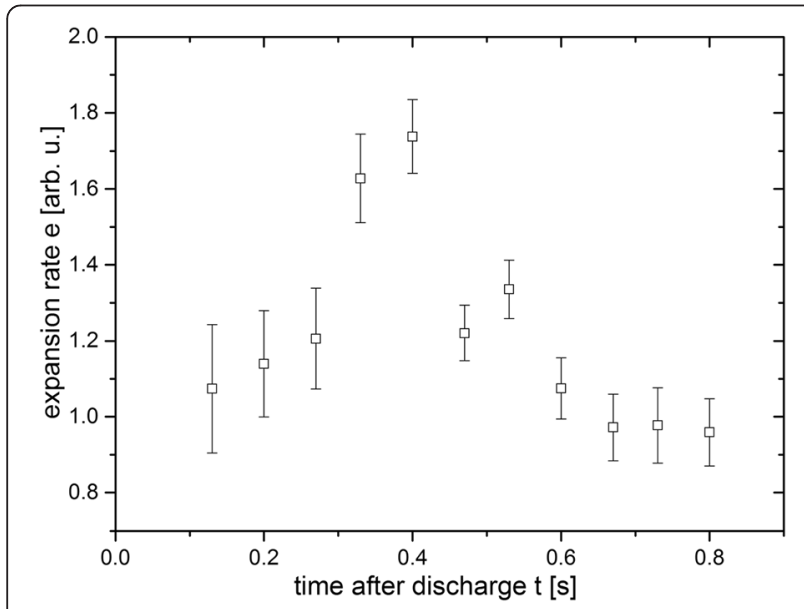

Fig. 8 Expansion rates $f(t)$ over time: In the depicted case (Eyja 2), the maximum expansion rate is reached at $0.4 \mathrm{~s}$, within the gas thrust stage. This time value, $t_{\exp }$ can be considered to be identical to the time of maximum volumetric expansion. The expansion rates $f(t)$ are defined by Eq. (2). The error bars represent the computed uncertainties according to error propagation in combination with a magmatic gas mass fraction of approximately $2 \%$ (Borisova et al. 2012; Keiding and Sigmarsson 2012) would indicate that at the zone of transition, a large fraction of the gas must have contained entrained air. Thus, with PVDM, we used for $\rho_{g}$-as a firstorder approximation-a density of $0.39 \mathrm{~kg} / \mathrm{m}^{3}$, corresponding to the density of $480{ }^{\circ} \mathrm{C}$ hot air at atmospheric pressure (using $1550 \mathrm{~m}$ a.s.l. and ambient temperature of $5^{\circ} \mathrm{C}$ ). With these values from Eq. (6), $\phi$ is estimated to be $3.0 \cdot 10^{-4}$.

The volumetric flow rate of a pulse $j_{\text {pulse }}$ can be described as that of an "ash package" through a cylindrical cross section with $d_{\text {trans }}\left(t_{I}\right)$ being its diameter and $v_{\text {trans }}$ being its flow velocity (see Fig. $5 \mathrm{a}$ ). Thus

$$
j_{\text {pulse }}=\left(\frac{d_{\text {trans }}\left(t_{I}\right)}{2}\right)^{2} \cdot \pi \cdot v_{\text {trans }}
$$

The measurement of $d_{\text {trans }}\left(t_{I}\right)$ and $v_{\text {trans }}$ allows us to estimate the mass flux of tephra $Q\left(t_{I}\right)$ by multiplying the volumetric flow rate with the density $\rho_{t}$ and the volume fraction $\phi$ of tephra:

$$
Q\left(t_{I}\right)=\rho_{t} \cdot \phi \cdot\left(\frac{d_{\text {trans }}\left(t_{I}\right)}{2}\right)^{2} \cdot \pi \cdot v_{\text {trans }}
$$

Although the actual temporal evolution of the mass flux of solids during a pulse, $Q(t)$, remains unknown (a hypothetical curve is shown in Fig. 5b (center)), it can be constrained by using two end members representing the minimum and maximum possible values, respectively.

The minimum time-dependent flow rate $Q_{\min }(t)$ is here defined by the initial peak of $Q\left(t_{I}\right)$ followed by an exponential decrease (Fig. 5b (left)), given by

$$
Q_{\min }(t)=Q\left(t_{I}\right) \cdot e^{-\frac{t}{\tau}}
$$

The duration $\tau$ represents the time period after which the mass flux $Q_{\min }(t)$ has decreased by a factor of $1 /$ e. This parameter was determined from videos by measuring the time between $t_{\mathrm{I}}$ and the instant $t_{\mathrm{III}}$, when the pulse diameter $d_{\text {trans }}\left(t_{\mathrm{III}}\right)$ has decreased to

$$
d_{\text {trans }}\left(t_{\mathrm{III}}\right)=d_{\mathrm{trans}}\left(t_{I}\right) / \sqrt{e}
$$

and

$$
\tau=t_{I}-t_{\mathrm{III}}
$$

The maximum time-dependent flow rate, $Q_{\max }(t)$, is characterized by a step function of duration $\tau$ (Fig. $5 \mathrm{~b}$ (right)) that would correspond to that of a cylindershaped ash package, as illustrated in Fig. 5a.

By considering the values bracketing the minimum and maximum time-dependent flow rate, it is possible to get a figure of the range of the mass flux of tephra, $Q_{\text {tot }}$, by integrating $Q_{\min }(t)$ and $Q_{\max }(t)$, and normalizing the results over the pulsation interval $t_{\text {pulse }}$ 


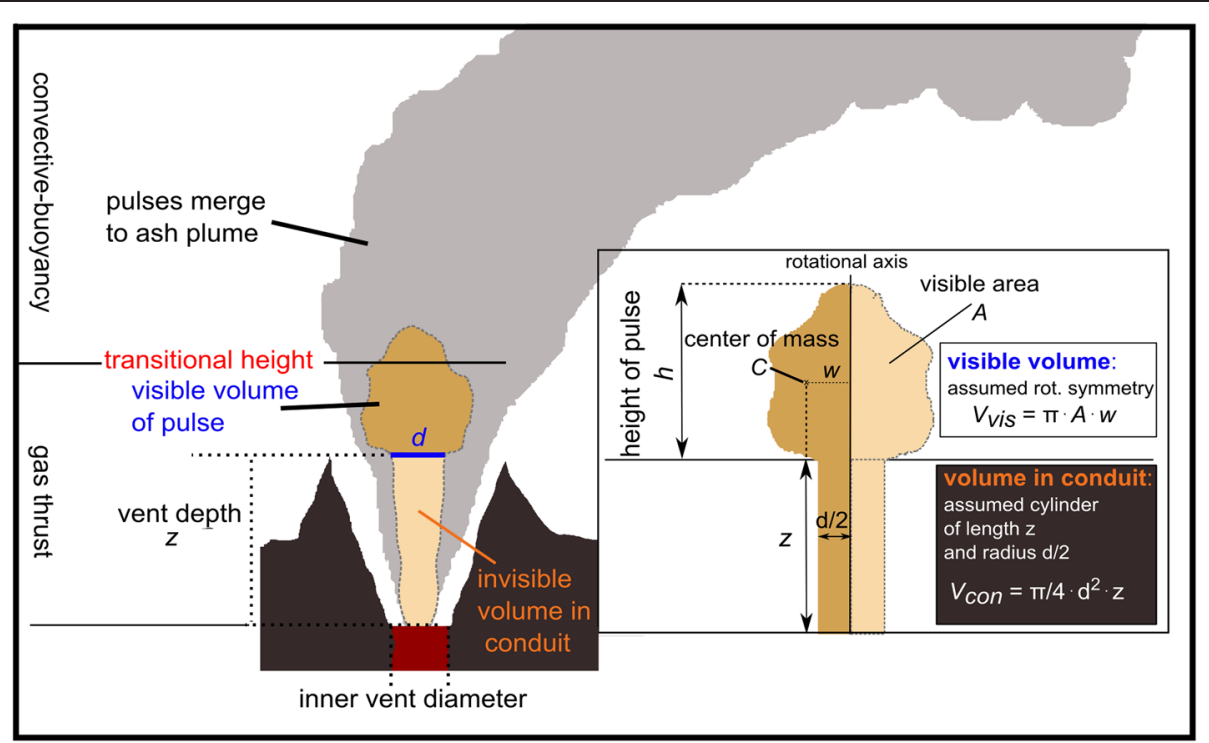

Fig. 9 Calculation of the pulse volume: The total volume of an ash pulse is composed of the visible top ( $\left.V_{\text {vis }}\right)$, and the hidden volume within the conduit $\left(V_{\text {con }}\right)$. By determining the pulse volume at transitional level $V_{\text {trans }}\left(t_{11}\right)$, it is possible to approximate the total mass within the volume. During the studied period, the vent geometry is specified by a distance between source level and vent exit (vent depth) $z$ of $51 \pm 7 \mathrm{~m}$ and an inner diameter of 8-15 m (Dürig et al. 2015)

$$
Q_{\text {tot }}=\frac{1}{t_{\text {pulse }}} \int_{0}^{\tau} Q(t) d t
$$

This leads to the two equations:

$$
\begin{aligned}
& Q_{\text {tot_min }}=\frac{\tau}{t_{\text {pulse }}} \cdot Q\left(t_{I}\right) \cdot(1-1 / e) \\
& Q_{\text {tot_max }}=\frac{\tau}{t_{\text {pulse }}} \cdot Q\left(t_{I}\right)
\end{aligned}
$$

where $Q_{\text {tot_min }}$ denotes the lower limit and $Q_{\text {tot_max }}$ the upper limit of $Q_{\text {tot}}$.

It should be noted that our measurement of $d_{\text {trans }}\left(t_{\mathrm{I}}\right)$ is made at a stage of the transition where it cannot be ruled out that some residual momentum of the negatively buoyant jet still exists. It implies that $\rho_{\text {pulse }}$ might be underestimated. This would lead to an underestimation of the flux when applying Eq. (13), supporting that

Table 4 Statistical results for pulse volumes $V_{\text {trams }}$ and pulse masses $m_{\text {tot }}$

\begin{tabular}{lll}
\hline Pulse type & $V_{\text {trams }}\left(\cdot 10^{5} \mathrm{~m}^{3}\right)$ & $m_{\text {tot }}\left(\cdot 10^{5} \mathrm{~kg}\right)$ \\
\hline Range & $0.2-10.5$ & $0.2-11.0$ \\
Average type 1 & 4.6 & 4.8 \\
Average type 2 & 1.6 & 1.7 \\
Wt. average & 2.0 & 2.1 \\
Wt. st. dev. & 1.5 & 1.6 \\
\hline
\end{tabular}

These values are based on 16 representative pulses between 8 and 10 May 2010. The volumetric values were computed by applying Eq. (3); the mass values were obtained by multiplying $V_{\text {trans }}$ with a density of $1.05 \mathrm{~kg} / \mathrm{m}^{3}$
$Q_{\text {tot_min }}$ can be considered as the minimum possible mass flux. On the other hand, by means of our PVDM procedure, velocity $v_{\text {trans }}$ is measured at a slightly later stage of transition, at $t_{\mathrm{II}}$, when part of the pulse is already at the transitional level. At this stage, the pulse density, because of an enhanced air entrainment, should be a little lower, implying an overestimation of $\rho_{\text {pulse }}$ and of the mass flux in our results. Since at this stage of the

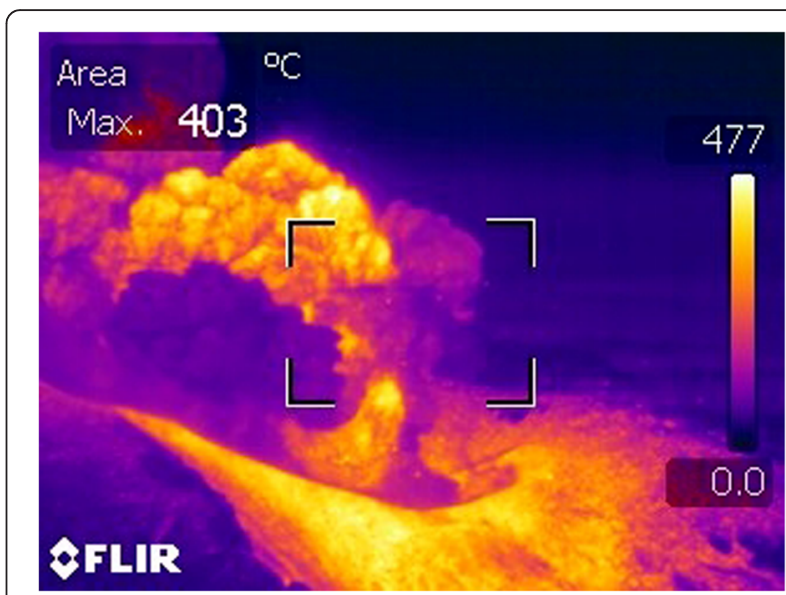

Fig. 10 Particles' temperature within a pulse: Example for a typical FLIR image taken at 8 May 2010. Settings: emissivity 0.92; atmospheric temperature $4.2^{\circ} \mathrm{C}$; relative humidity 0.50 ; transmission 0.91 . It shows an ash pulse suggesting a maximum temperature of $\sim 400{ }^{\circ} \mathrm{C}$ within the marked rectangular area and $\sim 480^{\circ} \mathrm{C}$ near the top, where the entrainment at the margins is expected to have the least effect. In the absence of more precise thermal data, the latter temperature value is used as approximation for the bulk temperature of the pulse 
beginning of buoyancy the pulse velocity does not change significantly (see Fig. 2d), this effect should only be of minor significance. This effect, combined with the step function used for the approximation of $Q(t)$, justifies the definition $Q_{\text {tot_max }}$ as the maximum theoretical mass flux.

In the following, for the sake of practical utility, we summarize the step-by-step PVDM procedure to determine the MER of a pulsating eruption, when analyzed from the near-vent videos:

1. Quantify the pulsation interval $t_{\text {pulse, }}$ i.e., the average time between two pulses. If necessary, classify the pulses (i.e., weak vs. strong) and determine the ratio to obtain type-specific values for $t_{\text {pulse }}$.

2. When analyzing the temporal evolution of an individual pulse within a video, identify the moment of transition into the buoyant stage, referred to as $t_{\mathrm{I}}$. This instant is, e.g., characterized by the onset of radial expansion and a significant change in the vertical velocity profile of the pulse front. Quantify the maximum pulse width at this moment $d_{\text {trans }}\left(t_{\mathrm{I}}\right)$. Its elevation defines the lower boundary of the transitional level.

3. Determine $t_{\mathrm{II}}$, defined as the moment when the pulse diameter at the lower boundary of transitional level is at maximum. The tip of the pulse at $t_{\mathrm{II}}$ defines the upper boundary of the transitional level.

4. Calculate $v_{\text {trans }}$ by tracking the pulse height evolution between $t_{\mathrm{I}}$ and $t_{\mathrm{II}}$.

5. Determine $t_{\mathrm{III}}$, defined by the moment when the pulse diameter at the lower boundary of transitional level has decreased to $d_{\text {trans }}\left(t_{\mathrm{I}}\right) / \mathrm{e}^{0.5}$.

6. Quantify the duration $\tau$ by applying Eq. (11).

7. Calculate the volume fraction of solids by applying Eq. (6).

8. With the resulting parameters, quantify $Q\left(t_{\mathrm{I}}\right)$ using Eq. (8). Subsequently, calculate $Q_{\text {tot_min }}$ by Eq. (13) and $Q_{\text {tot_max }}$ with Eq. (14) to determine the pulsespecific range of the total mass flux of solids $Q_{\text {tot }}$.

By applying steps 2 to 8 for a representative set of pulses, the average of $Q_{\text {tot_min }}$ and $Q_{\text {tot_max }}$ (weighted to the ratio of pulse types, if necessary) can be quantified. These numbers constrain the MER of the analyzed eruption.

In the case of Eyjafjallajökull 2010, we applied PVDM to 30 pulses (5 of type 1 and 25 of type 2). Choosing type-specific values for $t_{\text {pulse }}$ according to Table 2, the resulting mass flux values range between $0.4 \cdot 10^{4}$ and $5.1 \cdot 10^{4} \mathrm{~kg} / \mathrm{s}$. The averaged mass flux value and standard deviation are shown in Table 3. The weighted average mass flux values range between $(2.2 \pm 0.7) \cdot 10^{4} \mathrm{~kg} / \mathrm{s}$ for $Q_{\text {tot_min }}$ and $(3.5 \pm 1.0) \cdot 10^{4} \mathrm{~kg} / \mathrm{s}$ for $Q_{\text {tot_max }}$. These bounds result in an average mass eruption rate of approximately $(2.9 \pm 0.9) \cdot 10^{4} \mathrm{~kg} / \mathrm{s}$, which represents the mean value over the 35 min of videos analyzed during the 3 days of the second phase of the eruption. In this period, no significant changes were observed in the eruption behavior.

\section{Determination of pulse masses}

The PVDM approach was also applied to estimate the mass of tephra $m_{\mathrm{t}}$ and the mass of gas $m_{\mathrm{g}}$ (magmatic gas and entrained air) contained within an individual pulse by using

$$
m_{t}=\int_{0}^{\tau} Q(t) d t
$$

and

$$
m_{g}=\int_{0}^{\tau} Q_{g}(t) d t
$$

where $Q_{g}(t)$ denotes the mass flux of the gas fraction at $t$. The range of $m_{t}$ can be constrained by $m_{\mathrm{t}_{-} \min }$ and $m_{t \_\max }:$

$$
\begin{aligned}
& m_{t_{-} \min }=\tau \cdot Q\left(t_{I}\right) \cdot(1-1 / e) \\
& m_{t_{-} \max }=\tau \cdot Q\left(t_{I}\right)
\end{aligned}
$$

and the range of $m_{g}$ can be constrained by $m_{g \_\min }$ and $m_{g} \max :$

$$
\begin{aligned}
& m_{g_{-} \min }=\tau \cdot Q_{g}\left(t_{I}\right) \cdot(1-1 / e) \\
& m_{\mathrm{g}_{-} \max }=\tau \cdot Q_{g}\left(t_{I}\right)
\end{aligned}
$$

with

$$
Q_{g}\left(t_{I}\right)=\rho_{g} \cdot(1-\phi) \cdot\left(\frac{d_{\text {trans }}\left(t_{I}\right)}{2}\right)^{2} \cdot \pi \cdot v_{\text {trans }}
$$

The statistics of $m_{t \_ \text {max }}$ and $m_{g \_\max }$ are shown in Table 3. The mass of tephra transported by individual pulses ranged between $0.4 \cdot 10^{5} \mathrm{~kg}$ (minimum of $m_{t \_ \text {min }}$ ) and $3.7 \cdot 10^{5} \mathrm{~kg}$ (maximum of $m_{t_{-} \max }$ ). The ratio between the mass of solids $\left(m_{t}\right)$ and mass of gas (magmatic and entrained air) in the pulse $\left(m_{g}\right)$ is approximately $2: 1$.

\section{Results and discussion}

Temporal changes in the pulsating behavior-comparison 4 May versus 8-10 May

No significant changes between pulsation intervals of 8 May and 10 May could be detected (see Fig. 11). Due to the very short length of the available video clip, no statement can be made about potential changes in the pulsating behavior on 9 May. 


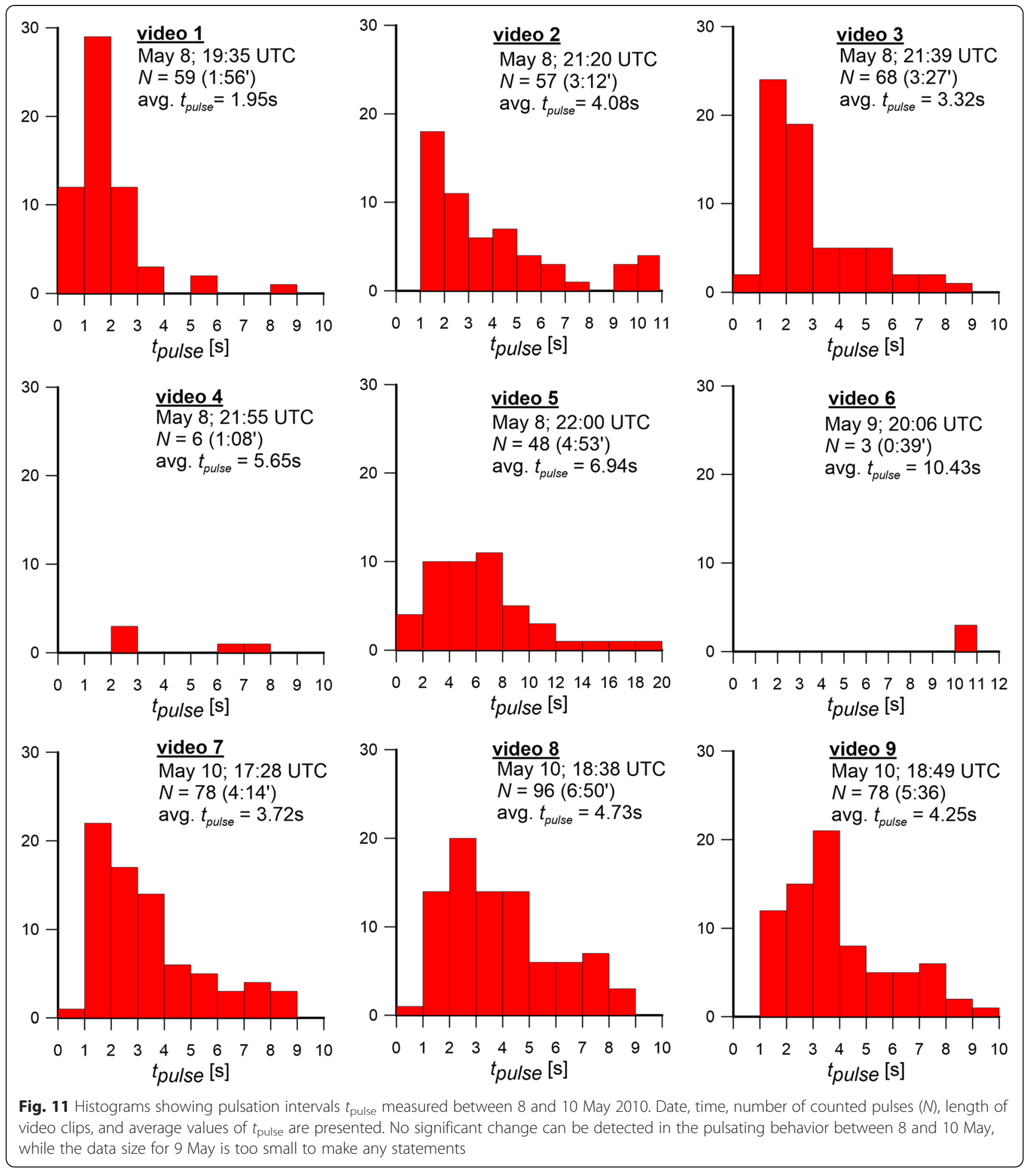

It is insightful to compare our findings on pulse characteristics with those reported for 4 May, which are based on measurements taken by a thermal camera mounted at $8.3-\mathrm{km}$ distance from the vent (Ripepe et al. 2013). Since the latter data set dates from the day before the onset of the second explosive stage, alterations between those and our results might be indicative for the possible general change in the pulsating behavior of Eyjafjallajökull.

While the range of initial pulse velocities $v_{0}$ was very similar in both periods (cf. Ripepe et al. 2013), the average of $v_{0}$ was clearly higher on 8-10 May being $65 \mathrm{~m} / \mathrm{s}$ instead of $45 \mathrm{~m} / \mathrm{s}$. The most prominent difference, however, is the significantly smaller average pulsation 
interval $t_{\text {pulse }}$ which dropped from $\sim 20 \mathrm{~s}$ (on 4 May) to $4.2 \mathrm{~s}$ (within the period studied in this article).

Although the video material analyzed for 8-10 May comprises only $35 \mathrm{~min}$ and cannot be assumed to be representative for the complete 2nd explosive stage, our findings indicate that the increased mass flux during 8-10 May compared to 4 May was to considerable extent manifested in approximately five times higher number of pulses per unit time.

\section{Discussion of errors and approximation of results}

According to the results of the PVDM, a type 1 pulse transports, on average, 2.3 times more mass of tephra than a type 2 pulse (see Table 3 ). However, due to the considerably higher frequency, the total mass flux is dominated by the weaker type 2 pulses, which account for $78 \%$ of the total mass flux. These details underline the advantage of using high-resolving near-field monitoring instruments for obtaining reasonably wellapproximated eruption source parameters, i.e., systems able to detect and quantify not only strong but also weaker ash pulses. Methods, which rely on the quantification of strong "all-out" ash pulses alone, ignoring the weaker pulses would seriously underestimate the actual MER. On the other hand, methods that assume the large pulses to be representative for a sustained eruption would result in an overestimation.

Considering a magmatic gas mass fraction of $2 \%$ at the source level (Borisova et al. 2012; Keiding and Sigmarsson 2012), the mass ratio between solids and gas of roughly 2:1 found at the transitional level implies that at this stage, the primary magmatic gas component constitutes only about $\sim 1.3 \%$ of the gas phase. This means that the dominant component of the gas phase is entrained air, which exceeds the amount of magmatic gas by a factor of more than 20 .

It is important to note that this finding is not just a consequence of the initial assumption of $\rho_{g}$ as represented by air. In fact, using, for example, the density of water vapor at $480{ }^{\circ} \mathrm{C}\left(0.29 \mathrm{~kg} / \mathrm{m}^{3}\right)$ as a proxy for magmatic gas instead of the density of hot air, a similar mass ratio $m_{t}: m_{g}$ results at transitional level (2.5:1), leading to a percentage of $\sim 1.5 \%$ for the magmatic gas fraction. These findings clearly indicate that approximating $\rho_{g}$ (the density of a pulse at transitional level) by taking the density of hot air is a consistent assumption.

It is a known fact for overpressured jets (Prandtl 1954), supported by experimental findings (e.g., Solovitz and Mastin 2009, Saffaraval et al. 2012, Saffaraval and Solovitz 2012), that near the source, along a downflow distance of approximately 30 vent diameters, air entrainment is reduced (Ricou and Spalding 1961). Our findings might be seen as an indication that this zone of limited air entrainment was below the level of transition.
Considering that the transitional level was at $100-200 \mathrm{~m}$ above the source level of the jets studied (50-150 m above vent exit), this would suggest that the pulses observed had an initial jet diameter of the order of $\sim 6 \mathrm{~m}$ or less.

The average of the pulse mass (i.e., the masses of the mixture, see Table 4), computed on the basis of the volumetric measurements described in the "Pulse volume at transitional level-methodology and results" section is

$$
m_{\text {tot }}=V_{\text {trans }} \cdot \rho_{\text {pulse }}
$$

With a pulse density of $1.05 \mathrm{~kg} / \mathrm{m}^{3}$, the mass obtained is $(2.1 \pm 1.6) \cdot 10^{5} \mathrm{~kg}$.

This value agrees well with the total mass that was independently obtained by applying PVDM and summing $m_{t} \max$ with $m_{g \_\max }$, resulting in the estimate $(2.4 \pm 1.2)$. $10^{5} \mathrm{~kg}$. Although our volumetric measurements are based on simple assumptions (a cylindrical shape of the invisible part of the pulse $V_{\text {con }}$ and a homogenous density balanced with the ambient value), the agreement of results encourage the use of the PVDM for obtaining quasi real-time estimations of the mass eruption rate.

While the volumetric measurements, as described in the "Pulse volume at transitional level-methodology and results" section, are quite time consuming and need some knowledge of the vent geometry, the PVDM can be easily applied to estimate the volumetric and even the mass flux during an eruption just on the basis of nearvent video material, given that the transitional level is within the field of vision. The only additional parameter is the internal pulse temperature, which is necessary for the estimation of $\rho_{g}$ and consequently $\phi$. An estimate of this parameter can be-as in our case-obtained by a thermal camera system, which is nowadays a commodity at active volcanoes observatories. Although it is arguable how representative FLIR measurements are for the bulk temperature of the eruptive mixture (see Harris 2013), values derived by thermal images can at least serve as a first estimate. Best results are obtained near the top of the pulse, where cooling at the interface by air entrainment has the least effect (see Fig. 10). Errors, e.g., due to inhomogeneities of the most internal part of the pulse, cannot be ruled out. In order to inspect the sensitivity of the PVDM results to pulse temperature, we can assume that the actual internal temperature was underestimated by $10 \%$ (i.e., $530{ }^{\circ} \mathrm{C}$ instead of $480{ }^{\circ} \mathrm{C}$ ). In that case, $\phi$ would be underestimated by $0.1 \cdot 10^{-4}$, meaning that the range of mass flux is shifted from $(2.2-3.5) \cdot 10^{4}$ to $(2.3-3.7) \cdot 10^{4} \mathrm{~kg} / \mathrm{s}$, which is still well within the suggested range of $(2.9 \pm 0.9) \cdot 10^{4} \mathrm{~kg} / \mathrm{s}$. Error analysis reveals that a temperature misfit of more than $750{ }^{\circ} \mathrm{C}$ would be needed for the result to be outside of the limits we provided. 
To verify the consistence of our model with the volcanological literature, our results were compared to independent estimates of the mass eruption rates during the Eyjafjallajökull eruption (see Table 5). According to photographs and C-band radar, in the observed periods during 8-10 May 2010 (see Table 1), the top of the eruption column had reached heights between 2.9 and $3.3 \mathrm{~km}$ over the vent (i.e., 4.6-5.0 km a.s.l.) (Arason et al. 2011; Gudmundsson et al. 2012).

With these plume heights, the mass eruption rate can be estimated by using various plume height models. Considering the relatively small sample size and the fact that the plume height-due to wind-displayed large variations in that period (Arason et al. 2011; Gudmundsson et al. 2012), the values calculated by the empirical models of Sparks et al. (1997) and Mastin et al. (2009) (adjusted by Gudmundsson et al. 2012) are in notably good agreement with the results obtained by the PVDM (see comparison in Table 5).

The numbers obtained by Ripepe et al. (2013) via infrasound measurements, however, exceed these results by a factor of $\sim 50$. This considerable deviation might be explained by the fact that their method is very sensitive to jet diameter at the source, which is inside the vent. This parameter was assumed to be $50 \mathrm{~m}$ by Ripepe et al. (2013), but recent findings by Dürig et al. (2015), based on ejecta trajectory analyses, suggest that in the 3-day period studied, the diameter of the inner vent was in fact considerably smaller, 8-15 m. Moreover, it has been argued that most of the pulses seem to have emerged only by a part of the vent, rather than completely filling the inner diameter (Dürig et al. 2015). These "punctuating" jets represent the type 2 pulses discussed in the present article, and according to our considerations above, we suggest that their diameter at the source had been smaller than $8 \mathrm{~m}$. The infrasound-derived results support this hypothesis, as with selecting a source diameter of, e.g., $6 \mathrm{~m}$ the infrasound-derived mass eruption rate would consistently fit the values obtained by PVDM.

Using plume heights and wind field data recorded during the eruption, the two numerical models presented by Devenish (2013) and Woodhouse et al. (2013) predict mass flux values which are an order of magnitude larger than the results obtained by the three empirical models listed in Table 5. These predictions are not supported by the empirical results based on the PVDM, since the factor of 10 (and more) would imply that the observed pulses would have been more than ten times denser at the transitional level than what we assumed (featuring a jet density of $\sim 10 \mathrm{~kg} / \mathrm{m}^{3}$, which would be greater than that of a jet with exclusively exsolved magmatic gas), compromising the occurrence of buoyancy. Although the maximum instantaneous eruption rate, $Q\left(t_{\mathrm{I}}\right)$, observed at the peak of the strongest (type 1) pulses reached this order of magnitude (Table 3), they only account for a relatively small part of the average eruption rate due to their low number relative to the weaker type 2 pulses. It is expected, however, that using a better constrained source diameter (i.e., the diameter of punctuating jets, than the vent diameter, like suggested for the infrasound model above) would increase the accuracy of the numerical models.

Our findings suggest that near-field measurements, as the ones proposed in the present paper, have considerable potential for the real-time assessment of the mass eruption rate and should represent a valuable complement for any eruption column monitoring network.

\section{Link between pulses and magma fragmentation events in the conduit}

According to the findings of $t_{\text {pulse }}$, a near-field monitoring instrument with the ability to detect distinct, discrete, eruptive pulses should resolve individual events with a minimum time interval of $0.8 \mathrm{~s}$ (which was the minimum time measured between consecutive pulses),

Table 5 Comparison of total mass flux estimates for the period of 8-10 May 2010

\begin{tabular}{lll}
\hline Model & MER $\left(10^{4} \mathrm{~kg} / \mathrm{s}\right)$ & Reference \\
\hline PVDM & $2.2-3.5$ & This study \\
Mastin PHM & $1.2-2.1$ & Mastin et al. 2009 \\
Adj. Mastin PHM & $1.9-3.3$ & Gudmundsson et al. 2012 \\
Sparks PHM & $2.2-3.6$ & Sparks et al. 1997 \\
Woodhouse PHM & $26.2-43.6$ & Woodhouse et al. 2013 \\
Devenish PHM & $26.3-38.2$ & Devenish 2013 \\
Ripepe infrasound & $84.5-109.9$ & Ripepe et al. 2013 \\
adj. Ripepe infrasound & $2.5-3.3$ & Ripepe et al. 2013 and Dürig et al. 2015
\end{tabular}

Mass eruption rates obtained by the pulse velocity derived model (PVDM) are compared with results from plume height models (PHM) and infrasound derived values. Remarks: 1) Using observed plume heights of 2.9-3.3 km as input parameter, 2) using a windspeed of $20 \mathrm{~m} / \mathrm{s}$ at $500 \mathrm{hPa}(\sim 5.2 \mathrm{~km}$ height) as input parameter, 3) cylindrical conduit with a diameter of $50 \mathrm{~m}$ was assumed, and 4) source diameter of $6 \mathrm{~m}$ was assumed, $40-75 \%$ of total diameter according to Dürig et al. (2015); see text for details 
requiring a minimum sampling rate of 10 samples/second. The fact that $t_{\text {pulse }}>t_{\exp }$ in all the observed cases implies that it is possible-at least under conditions similar to those observed for this study-to record directly the crucial stages of evolution of each pulse without the interference of the subsequent one. It is a mandatory prerequisite for obtaining the main source parameters of discrete eruptive events in real time. Such a pulsating behavior can be interpreted as the result of discrete magma fragmentation events in the conduit, a hypothesis which is, e.g., corroborated by the records of infrasonic transients associated with the pulses (Ripepe et al. 2013). The small variation of $t_{\exp }$ found for Eyjafjallajökull pulses underlines the high degree of similarities in the expansion dynamics, as also shown by Fig. 7. This fact suggests that the pulses were caused by similar eruption mechanisms, which lead to a similar kinetic energy release after magma fragmentation (e.g., Dürig et al. 2012a, 2012b).

In order to check the link between the pulse emerging from the vent and the post-fragmentation energetics in the conduit, we analyzed the videos of experimentally generated ash pulses under controlled initial conditions that reflect the kinetic energy release in magma fragmentation (Dellino et al. 2010; Dellino et al. 2014). The same photogrammetric method used for the Eyjafjallajökull eruption was employed for analyzing experiments videos (see Fig. 6b). In the experimental runs, $80-220 \mathrm{~kg}$ of both "cold" (298 K) and "hot" (543 K) ash were ejected from a steel conduit (diameter. $0.6 \mathrm{~m}$; length, up to $4 \mathrm{~m}$ ) by driving pressures between 90 and 180 bar (9-18 MPa) (Dellino et al. 2010, 2014).

Two representative runs are displayed in Fig. 7 (illustrated by unbroken lines). In the experiments, the evolution of the ash pulses within the gas thrust regime is similar to that observed at Eyjafjallajökull. Just in the advanced stages (after approximately $0.7 \mathrm{~s}$ ), the experimental curves show a slightly larger variation than those of the natural events, probably because of a larger wind effect on the expansion behavior of the experimental plume, where the volume of the erupted ejecta was much less than in the Eyjafjallajökull eruption.

In the experimental case, the analysis of the expansion rates reveals that the mean value of $t_{\exp }$ is $0.41 \mathrm{~s}$ with a standard deviation of $0.07 \mathrm{~s}$. This means that the times of maximum expansion rates are strikingly similar to those obtained for the Eyjafjallajökull pulses. According to the considerations made in "Time of maximum expansion rates", $t_{\exp }$ is controlled by the mechanism of kinetic energy release of ash particles upon magma fragmentation. Also, the experiments are "fine-tuned" in a way to transfer mechanical energy from the early gas expansion phase to the particle load with a time scale compatible with magmatic fragmentation (see Dellino et al. 2010). Therefore, the similarity of $t_{\exp }$ between actual eruptive pulses and experiments suggests that the loading relaxation history that underlies the impulsive coupling of ash particle generation by magmatic fragmentation can be reproduced by using comparable specific kinetic energies and time scales. The good fit to experimental data calibrated to magma fragmentation energetics could be the foundation for the development of new monitoring techniques, potentially allowing the reconstruction of the triggering mechanisms of explosive eruptions.

\section{Conclusions}

Near-field video analyses have shown that magmatic 2010 Eyjafjallajökull activity of 8-10 May was characterized by discrete pulses with an average time interval of $4.2 \mathrm{~s}$ and a minimum time interval of $0.8 \mathrm{~s}$. The intensity of pulses as well as their intervals showed strong variations, so did also the mass flux of the analyzed jets that was quantified by a simple volume flux model. The PVDM utilizes the assumption that the pulse density is close to that of the surrounding air when entering the transitional level between the gas thrust and the convective buoyant regime. In the case we studied, the bulk of the emitted tephra is transported by the more numerous weaker pulses, which contribute about $3 / 4$ of the overall mass flux (i.e., mass eruption rate) which for the Eyjafjallajökull eruption during 8-10 May 2010 is found between 2.2 and $3.5 \cdot 10^{4} \mathrm{~kg} / \mathrm{s}$. The resulting mass flux is in good agreement with empirical plume height-based models. This suggests that near-field observations, as the ones used in this paper, can be a useful tool in monitoring explosive volcanic eruptions.

The expansion rates of tephra pulses emitted out of the vent always reached their maximum well before the occurrence of the subsequent pulse. This condition needs to be verified during other eruptions, in order to demonstrate the general applicability of our method. The comparison of results obtained for the Eyjafjallajökull pulses and the experimental generation of large-scale ash plumes (Dellino et al. 2010, 2014) shows a similarity in the time scale of coupling of kinetic energy to the mass of particles released upon magma fragmentation.

These findings confirm that for the Eyjafjallajökull eruption, a sustained plume observed from distance actually was the result of the merging of many discrete, closely timed magma fragmentation events occurring within the volcanic conduit. We look forward to the verification of such a concept for other, even larger magnitude eruptions, in order to make this link between magma fragmentation and plume transportation more constrained.

Competing interests

There are neither financial nor non-financial competing interests. 


\section{Authors' contributions}

TD performed the video analyses and led the development of the model and ideas presented in collaboration with MTG, SK, BZ, PD, FD, and RB. The videos analyzed were taken and kindly provided by MR. All authors contributed to the ideas presented and took part in writing the paper.

\section{Acknowledgements}

The work of TD is funded by the EU FP7 supersite project FutureVolc. Photos and FLIR images obtained on 8 May were acquired by Björn Oddsson and Thordís Högnadóttir, University of Iceland. Fabio Dioguardi is thanked for his support and for fruitful discussions on ash plume dynamics. We would like to thank the editor Shan de Silva and express our gratitude to Larry G. Mastin, Maurizio Ripepe, and an anonymous reviewer for their most useful comments and suggestions which helped us to improve the quality of our paper.

\section{Author details}

${ }^{1}$ Nordvulk, Institute of Earth Sciences, University of Iceland, Sturlugata 7, 107, Reykjavík, Iceland. ${ }^{2}$ Physikalisch-Vulkanologisches Labor, Universität Würzburg, Pleicherwall 1, 97070 Würzburg, Germany. ${ }^{3}$ Dipartimento di Scienze della Terra e Geoambientali, Università di Bari, Via Orabona 4, 70125 Bari, Italy.

${ }^{4}$ Taubenstr, 1, 82223 Eichenau, Germany.

\section{Received: 18 June 2015 Accepted: 28 October 2015}

\section{Published online: 05 November 2015}

\section{References}

Arason P, Peterson GN, Bjornsson H (2011) Observations of the altitude of the volcanic plume during the eruption of Eyjafjallajökull, April-May 2010. Earth Syst Sci Data 3:9-17. doi:10.5194/essd-3-9-2011

Bjornsson H, Magnusson S, Arason P, Petersen GN (2013) Velocities in the plume of the 2010 Eyjafjallajökull eruption. J Geophys Res Atmos 118:1-14. doi:10.1002/jgrd.50876

Bonadonna C, Folch A, Loughlin S, Puempel H (2012) Future developments in modelling and monitoring of volcanic ash clouds: outcomes from the first IAVCEI-WMO workshop on ash dispersal forecast and civil aviation. Bull Volcanol 74:1-10. doi:10.1007/s00445-011-0508-6

Borisova AY, Toutain JP, Stefansson A, Gouy S, de Parseval P (2012) Processes controlling the 2010 Eyjafjallajökull explosive eruption. J Geophys Res 117, B05202. doi:10.1029/2012JB009213

Bursik M, Jones M, Carn S, Dean K, Patra A, Pavolonis M, Pitman EB, Singh T, Singla P, Webley P, Björnsson H, Ripepe M (2012) Estimation and propagation of volcanic source parameter uncertainty in an ash transport and dispersal model: application to the Eyjafjallajokull plume of 14-16 April 2010. Bull Volc 74:2321-2338

Büttner R, Zimanowski B, Röder H (2000) Short time electrical effects during volcanic eruptions: experiments and field measurements. J Geophys Res 105, 2819-2828. doi:10.1029/1999JB900370.

Chojnicki KN, Clarke AB, Phillips JC, Adrian RJ (2015) Rise dynamics of unsteady laboratory jets with implications for volcanic plumes. Earth Planet Sci Lett 412:186-196. doi:10.1016/j.epsl.2014.11.046

Dellino P, Dioguardi F, Zimanowski B, Büttner R, Mele D, La Volpe L, Sulpizio R, Doronzo DM, Sonder I, Bonasia R, Calvari S, Marotta E (2010) Conduit flow experiments help constraining the regime of explosive eruptions. J Geophys Res 115, B04204. doi:10.1029/2009JB006781

Dellino P, Gudmundsson MT, Larsen G, Mele D, Stevenson JA, Thordarson T, Zimanowski B (2012) Ash from the Eyjafjallajökull eruption (Iceland): fragmentation processes and aerodynamic behavior. J Geophys Res 117:B00C04. doi:10.1029/2011JB008726

Dellino P, Dioguardi F, Mele D, D'Addabbo M, Zimanowski B, Büttner R, Doronzo DM, Sonder I, Sulpizio R, Dürig T, La Volpe L (2014) Volcanic jets, plumes, and collapsing fountains: evidence from large-scale experiments, with particular emphasis on the entrainment rate. Bull Volcanol 76:834. doi:10.1007/s00445-014-0834-6

Devenish BJ (2013) Using simple plume models to refine the source mass flux of volcanic eruptions according to atmospheric conditions. J Volcanol Geotherm Res 256:118-127. doi:10.1016/j.jvolgeores.2013.02.015

Dürig T, Dioguardi F, Büttner R, Dellino P, Mele D, Zimanowski B (2012a) A new method for the determination of the specific kinetic energy (SKE) released to pyroclastic particles at magmatic fragmentation: theory and first experimental results. Bull Volcanol 74:895-902. doi:10.1007/s00445-011-0574-9
Dürig T, Sonder I, Zimanowski B, Beyrichen H, Büttner R (2012b) Generation of volcanic ash by basaltic volcanism. J Geophys Res 117, B01204. doi:10.1029/2011JB008628

Dürig T, Gudmundsson MT, Dellino P (2015) Reconstruction of the geometry of volcanic vents by trajectory tracking of fast ejecta-the case of the Eyjafjallajokull 2010 eruption (Iceland). Earth Planets Space 67(1):64. doi:10.1186/s40623-015-0243-x

Gerst A, Hort M, Aster RC, Johnson JB, Kyle PR (2013) The first second of volcanic eruptions from the Erebus volcano lava lake, Antarctica-energies, pressures, seismology, and infrasound. J Geophys Res 118:3318-3340. doi:10.1002/jgrb.50234

Gudmundsson MT, Thordarson T, Höskuldsson A, Larsen G, Björnsson H, Prata FJ, Oddsson B, Magnússon E, Högnadóttir T, Petersen GN, Hayward CL, Stevenson JA, Jónsdóttir I (2012) Ash generation and distribution from the April-May 2010 eruption of Eyjafjallajökull, Iceland. Sci Rep 2:572. doi:10.1038/srep00572

Harris AJL (2013) Thermal remote sensing of active volcanoes. University Press, Cambridge

Johnson JB, Ripepe M (2011) Volcano infrasound: a review. J Volcanol Geotherm Res 206:61-69. doi:10.1016/j.jvolgeores.2011.06.006

Kaminski E, Tait S, Ferrucci F, Martet M, Him B, Husson P (2011) Estimation of ash injection in the atmosphere by basaltic volcanic plumes: the case of the eyjafjallajökull 2010 eruption. J Geophys Res 116:B00C02. doi:10.1029/2011JB008297

Keiding JK, Sigmarsson O (2012) Geothermobarometry of the 2010 Eyjafjallajökull eruption: New constraints on Icelandic magma plumbing systems. J Geophys Res 117:B00C09. doi:10.1029/2011JB008829

Langmann B, Folch A, Hensch M, Matthias V (2011) Volcanic ash over Europe during the eruption of Eyjafjallajökull on Iceland, April-May 2010. Atmos Env 48:1-8. doi:10.1016/.atmosenv.2011.03.054

Marchetti E, Ripepe M, Harris AJL, Delle Donne D (2009) Tracing the differences between Vulcanian and Strombolian explosions using infrasonic and thermal radiation energy. Earth Planet Sci Lett 279:273-281. doi:10.1016/j.epsl.2009.01.004

Mastin LG, Guffanti M, Servranckx R, Webley P, Barsotti S, Dean K, Durant A, Ewert JW, Neri A, Rose WI, Schneider D, Siebert L, Stunder B, Swanson G, Tupper A, Volentik M, Waythomas CF (2009) A multidisciplinary effort to assign realistic source parameters to models of volcanic ash-cloud transport and dispersion during eruptions. J Volcanol Geotherm Res 186:10-21. doi:10.1016/j.jvolgeores.2009.01.008

Patrick MR, Harris AJL, Ripepe M, Dehn J, Rothery DA, Calvari S (2007) Strombolian explosive styles and source conditions: insights from thermal (FLIR) video. Earth Planet Sci Lett 69:769-784. doi:10.1007/ s00445-006-0107-0

Prandtl L (1954) Essentials of fluid mechanics. Blackie, Glasgow

Ricou FP, Spalding DB (1961) Measurements of entrainment by axisymmetrical turbulent jets. J Fluid Mech 11:21-32. doi:10.1017/S0022112061000834

Rietze M (2010) Iceland 6.5.2010-11.5.2010 Eyjafjallajökull Video Clips. http:// www.mrietze.com/iceland10-2.htm. Accessed 18 Jun 2014.

Ripepe M, Bonadonna C, Folch A, Delle Donne D, Lacanna G, Marchetti E, Höskuldsson A (2013) Ash-plume dynamics and eruption source parameters by infrasound and thermal imagery: the 2010 Eyjafjallajökull eruption. Earth Planet Sci Lett 366:112-121. doi:10.1016/j.epsl.2013.02.005

Saffaraval F, Solovitz SA (2012) Near-exit flow physics of a moderately overpressured jet. Phys Fluids 24:086101. doi:10.1063/1.4745005

Saffaraval F, Solovitz SA, Ogden DE, Mastin LG (2012) Impact of reduced near-field entrainment of overpressured volcanic jets on plume development. J Geophys Res 117:B5. doi:10.1029/2011JB008862

Schneider CA, Rasband WS, Eliceiri KW (2012) NIH Image to ImageJ: 25 years of image analysis. Nat Methods 9:671-675

Solovitz SA, Mastin LG (2009) Experimental study of near-field air entrainment by subsonic volcanic jets. J Geophys Res 114:B10. doi:10.1029/2009JB006298

Sparks RSJ (1986) The dimensions and dynamics of volcanic eruption columns. Bull Volcanol 48:3-15.

Sparks RSJ, Bursik MI, Carey SN, Gilbert JS, Glaze LS, Sigurdsson H, Woods AW (1997) Volcanic Plumes. Wiley \& Sons, Chichester.

Taddeucci J, Scarlato P, Capponi A, Del Bello E, Cimarelli C, Palladino DM, Kueppers U (2012) High-speed imaging of Strombolian explosions: the ejection velocity of pyroclasts. Geophys Res Lett 39, L02301. doi:10.1029/ 2011GL050404 
Valade S, Harris AJL, Cerminara M (2014) Plume ascent tracker: interactive matlab software for analysis of ascending plumes in image data. Comput Geosci 66:132-144. doi:10.1016/j.cageo.2013.12.015

Vöge M, Hort M (2009) Installation of a Doppler radar monitoring system at Merapi volcano, Indonesia. IEEE Trans Geosci Remote Sens 47:251-271. doi:10.1109/TGRS.2008.2002693

Woodhouse MJ, Hogg AJ, Phillips JC, Sparks RSJ (2013) Interaction between volcanic plumes and wind during the 2010 Eyjafjallajökull eruption, Iceland. J Geophys Res 118:1-18. doi:10.1029/2012JB009592

Submit your manuscript to a SpringerOpen ${ }^{\odot}$ journal and benefit from:

- Convenient online submission

- Rigorous peer review

- Immediate publication on acceptance

- Open access: articles freely available online

- High visibility within the field

- Retaining the copyright to your article

Submit your next manuscript at $\gg$ springeropen.com 